\title{
Aquarium Maintenance Related Diseases
}

\author{
Antonio V. Sykes, Kerry Perkins, Panos Grigoriou, \\ and Eduardo Almansa
}

\begin{abstract}
This chapter reviews the mechanical (physical) and chemical (water quality) related pathologies that have been reported since cephalopods are maintained, reared or cultured in captivity. For the first time, it builds up on the existing knowledge from researchers and aquarists (which are represented as authors of the chapter) in order to provide the most updated and inclusive revision on this theme. It is organized in terms of pathologies that are reported and eventual described for one or more species, which are commonly kept for research and display purposes, and exemplified with photos when possible. It includes pathologies of the mantle, arms, eyes, shell; egg infections, malformations of the shell and eggs; and causes of disease or mortality related with water quality focusing on $\mathrm{pH}$ and trace elements.
\end{abstract}

\section{Keywords}

Cephalopoda - Chemical related pathologies - Egg infections - Malformations Shell fracture - Skin wounds

\subsection{Introduction}

Since 2013, cephalopods used in experimentation are protected in the European Union through the application of Directive 2010/63/EU (EU 2010). The application of this law generated an impact in research and aquaculture (Sykes et al.

A. V. Sykes $(\bowtie)$

Centro de Ciências Do Mar, Universidade Do Algarve|CCMAR, Campus de Gambelas, Faro, Portugal

e-mail: asykes@ualg.pt

K. Perkins

Sea Life Brighton-Merlin Entertainments, Marine Parade,

Brighton, BN2 1TB, UK

e-mail: Kerry.Perkins@merlinentertainments.biz

P. Grigoriou

HCMR, Gournes Pediados, P.O. Box 221471003 Irakleion, Crete, Greece

e-mail: pgrigoriou@her.hcmr.gr

\section{E. Almansa}

Instituto Español de Oceanografía, Centro Oceanográfico de Canarias, Santa Cruz de Tenerife, Canary Islands, Spain

e-mail: eduardo.almansa@ieo.es
2012; Ponte et al. 2013; Smith et al. 2013; Fiorito et al. 2014; Di Cristina et al. 2015). Unfortunately, at time of publication (2010) and until the end of 2017, the Directive omitted important information regarding the housing and husbandry conditions of this class. This has prompted the cephalopod community to join and write the first set of guidelines for the use of this class in the laboratory (Fiorito et al. 2015). Under this framework and that of COST Action CephsInAction (FA1301-http://www.cephsinaction.org/), the community has suggested the definition of mandate minima [minimal requirements in Annex III (Care and Accommodation) and Annex IV (Humane killing)] for cephalopod to be included in the update of Directive 2010/63/EU. Through a consensus approach on published data, the community has established the species-specific requirements for the care and accommodation of cephalopods.

The health and welfare of cephalopods are directly related to how these animals are housed and treated. 'Pathologies registered under captive conditions derive most of the times from bad welfare practice' (Sykes and Gestal 2014). Interestingly, despite this cephalopods have been used as laboratory animals 
for more than a century (Dröscher 2016), most of the existing literature regarding pathologies observed in cephalopods in captivity was published at the end of the 1980s and beginning of 1990 s, resulting from the booming interest on culturing individuals of this class (Sykes et al. 2014b).

Pathologies in cephalopods are related to the method of capture, transportation (from the type of container used, to biting or cannibalism, when animals are transported in group), handling (from rough materials used in nets to slipping from the hand of the operator), housing (seawater systems not meeting the minimal requirements of seawater quality, space, illumination, etc.) and husbandry (live prey may become predators and try to eat the cephalopod) conditions (Forsythe et al. 1987; Hanlon 1990; Boyle 1991; Oestmann et al. 1997; Fiorito et al. 2015). Good (positive) or bad (negative) welfare practice in research, maintenance, rearing or culture conditions will determine the existence of pathologies in cephalopods in any of these. The cause of pathologies in cephalopods may be divided in viral, bacterial, fungi, parasite, chemical and mechanical (Sykes and Gestal 2014). This chapter focuses on mechanical (physical) and chemical (water quality) related pathologies, which will be presented according to the pathologies observed in one or more situations identified above for all.

\subsection{Mechanical (Physical) Damage Related Pathologies}

\subsubsection{Skin Wounds}

Apart from being the outer barrier of the muscle tissue beneath, the skin of coleoid cephalopods is used to express behaviour through the dynamic patterns of the chromatophores (How et al. 2017), communication and camouflage (Hanlon and Messenger 1996). The skin also has cells with the ability to sense light (Kingston et al. 2015) and, eventually, smell (Campinho et al. 2017). This integumentary system is composed by (from top to bottom): (a) a mono-stratified epidermis consisting of columnar epithelial cells with a microvillous border (Smith et al. 2011), which is intermingled with mucus-secreting cells (Hanlon et al. 1984); and (b) a deeper dermis (thicker than the previous), composed of connecting tissue (with numerous blood vessels and nerves and some amoebocytes), and containing chromatophores, iridophores, and leucophores (Andouche and Bassaglia 2016).

Because of the delicate nature of the skin, the handling, transportation and housing of cephalopods should be made with utmost care to prevent tears or other trauma to the skin tissue. Any skin wound is an open door for opportunistic secondary infections (particularly bacterial), which can be fatal if untreated (Fiorito et al. 2015). Hanlon et al. (1984) and Hanlon and Forsythe (1990a) characterized four stages of ulceration: (a) Stage 1-The epidermis is destroyed mostly or completely, chromatophores become nonfunctional, with oblong or elliptical shape or they disintegrate (originating a slight grey colour in the skin). The dermis becomes thicker with collagen, but the layers of muscle cells are disrupted, and the tissue display an increased number of amoebocytes and blood vascular vessels; (b) Stage 2-Total destruction of the epidermis, and total destruction of the chromatophores with ulcerated zones increasing in size over the mantle surface. Amoebocytes are present in the superficial layers of the dermis. Bacteria populate and embed exposed surface and tissue; (c) Stage 3-Full penetration of the skin and muscle layers (deep wounds). Fast progression of ulcers and bacteria spread to the ventral part of the mantle; Stage 4-Spreading of lesions to the head and arms. Wounds in Stages 3 and 4 are fatal. All cephalopods are known to be susceptible to the infection of the skin by bacteria (Forsythe et al. 1987; Hanlon et al. 1988). The most common secondary bacterial infections associated with skin wounds were reported by Sherrill et al. (2000), Hanlon et al. (1984), and Ford et al. (1986) for cuttlefish, octopus and squid species, respectively. Nonetheless, cephalopods are known to have the ability to fully recover from arm injuries or amputation through regeneration (Feral 1978, 1979, 1988; Rohrbach and Schmidtberg 2006; Tressler et al. 2014; Shaw et al. 2016).

\subsubsection{Mantle and Arms}

Mantle tip damage, resulting from hitting the tank walls, is known to occur in octopus, squid and cuttlefish (Forsythe et al. 1987; Hanlon et al. 1988; Scimeca and Oestmann 1995; Hanley et al. 1998; Scimeca 2011). It is characterized by extensive, deep ulcerative dermatitis and cellulitis (Fig. 13.1a, b), with exposure of the cuttlebone tip in cuttlefish (Fig. 13.1e, f, g). One way of mitigating such damage is to apply the soft-sided tanks technology (Hanley et al. 1999). Another way is lowering density or increasing the sex ratio of females (Sykes et al. unpublished results). Ford et al. (1986) reported a skin lesion that led to the split of the mantle and exposure of the gladius in Lolliguncula brevis.

In octopus and cuttlefish, the mere contact of the suckers of one individual to another is sufficient to cause skin damage (Forsythe et al. 1987; Hanlon et al. 1988; Hanley et al. 1998). Cuttlefish copulate on a head-to-head position, where the arms of both are tangled and males exert some strength to keep the female in the position. Males also fight for the opportunity of copula (either with a female or another smaller male, if the latter is showing signs that may lead to sexual misleading; Brown et al. 2012) and this will result in multiple skin wounds (Fig. 13.1d, g). Either cuttlefish or octopus can show extended biting wounds (Fig. 13.1c) resulting from the latter, with eventual internal organ exposure [Fig. 6.3 in Sykes and Gestal (2014)]. 

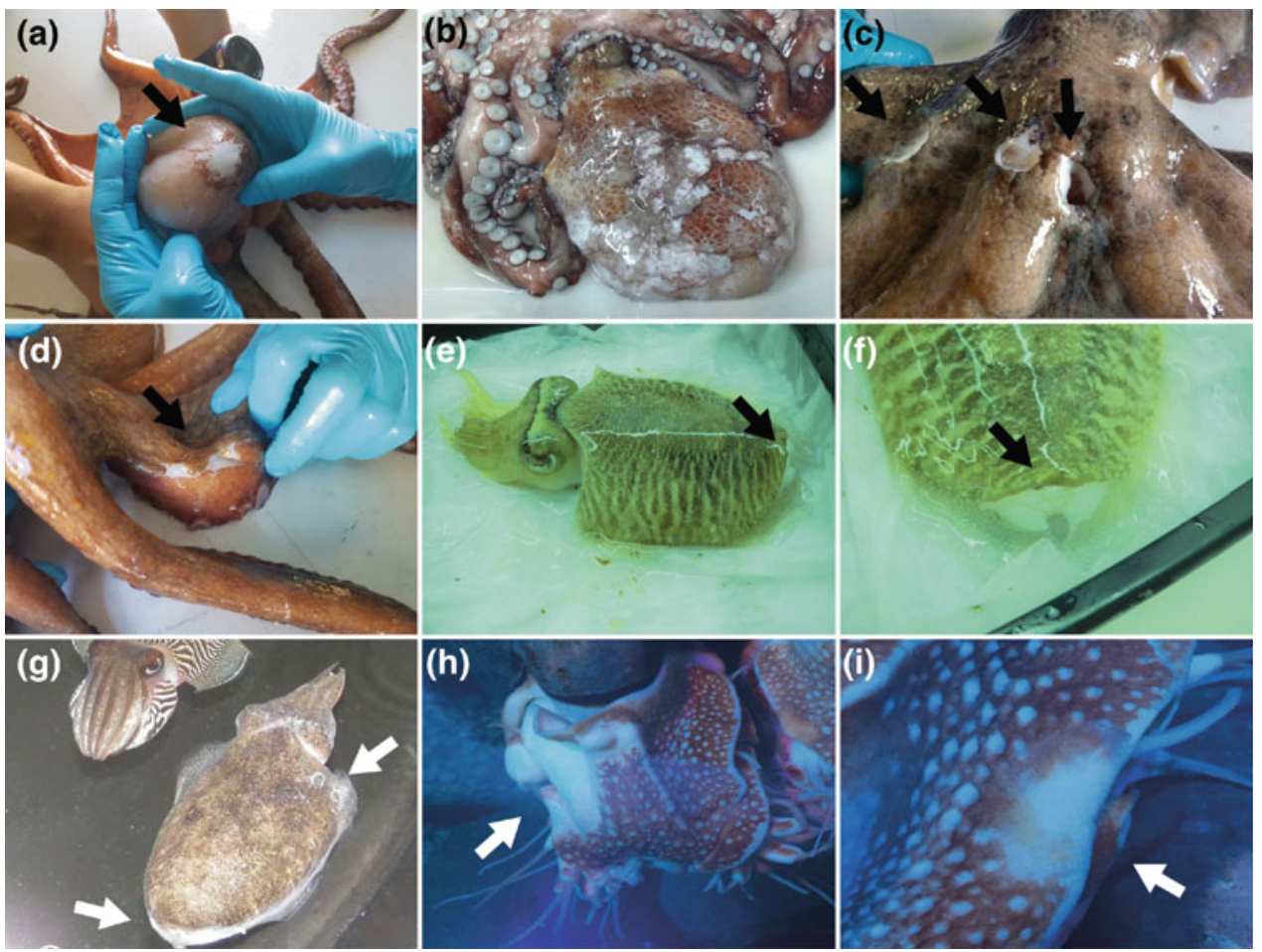

Fig. 13.1 Mechanical damage of cephalopod skin: a Skin abrasion (ulcerative dermatitis of the mantle apex) in the head of juvenile Octopus vulgaris (probably derived from hitting the tank wall); b Generalized skin wound with probable bacterial sepsis in a senescent O. vulgaris female; c Extended biting marks in the connection of the arms with the head in an $O$. vulgaris juvenile caused by male fighting; d Minor biting marks in the arm of an $O$. vulgaris juvenile; e Ulcerative dermatitis of the mantle apex in Sepia officinalis, due to hitting the tank

There are reports (Reimschuessel and Stoskopf 1990; Budelmann 1998, 2010) regarding autophagy or automutilation syndrome (OAS) to occur in at least four species of octopus (Octopus dolfleini, O. vulgaris, O. bimaculoides and $O$. maya). This syndrome is reported to affect both mantle and arms. There is no consensus on if it caused by a substance (released by the octopus) or eventually by a virus or bacteria.

In squid, skin lesions related to tank wall contact often result in internal infections (apart from the skin itself), which are chronic and develop slowly, requiring weeks or months to be fatal (Forsythe et al. 1987). According to the same authors, the most common of these infections is a localized necrosis of mantle tissue that surrounds the wound, spreading from the mantle apex towards the head and looking like 'an opaque dagger-shaped abscess in the lateral mantle tissue'.

In Nautilus, Scimeca (2011) reported skin abrasion, associated with a deep infection originated by a fungus, which generate pigment loss (Fig. 13.1h, i). There have also been several anecdotal reports of hood discolouration, with fast spreading growth, being these patches often colonised by other pathogens (Barord 2014). wall; $\mathbf{f}$ Detail image of wound described in E, where the lack of skin and the appearance of the distal tip of the cuttlebone is now visible; g Mantle skin wounds in female S. officinalis (arrow on the left shows a similar ulcerative dermatitis of the mantle apex as in E and F, while the arrow on the right shows multifocal ulcerative dermatitis provoked by male cuttlefish suckers during the act of copulation); $\mathbf{h}$ Skin wound near the mantle cavity in Nautilus pompilius; i Skin wound in the tissue right above the eye in $N$. pompilius

\subsubsection{Eyes}

Pathologies of the eyes in cephalopods have been reported to occur in octopus, squid and cuttlefish (Forsythe et al. 1987; Hanlon 1990; Sykes and Gestal 2014).

Forsythe et al. (1987) reported that the eye ball of octopuses may sometimes swell and rupture, being fatal within 2 days. According to these same authors, Hanlon et al. (1989b) and Hanlon and Forsythe (1990a), a similar condition may also occur in squid. However, in the latter the cause is the incrustation of bacterial colonies due to tissue abrasion, which turns the lens and the corneal covering of the eye opaque and the eye larger than normal. This condition may also be found in octopus and cuttlefish (Fig. 13.2a and b, respectively).

Idiopathic bulbus protusions of one or two eyes have been registered during reproduction in cuttlefish (Sykes and Gestal 2014) and affect both male and female (Fig. 13.2b, c). According to Hanley et al. (1998), this condition also affects juveniles and may eventually lead to the eye pathology previously described above. There are no reports of alike idiopathic bulbus protusions of the eye in nautilus. However, a similar skin abrasion, associated with a deep infection 
Fig. 13.2 Mechanical damage of cephalopod skin 2: a Opaque lens in $O$. vulgaris; $\mathbf{b}$ Opaque lens and idiopathic bulbous protrusions of the eye in $S$. officinalis males (on the left and right individuals, respectively); c Idiopathic bulbous protrusions of both eyes in a $S$. officinalis female; d Skin wound in the tissue right above the eye in Nautilus pompilius
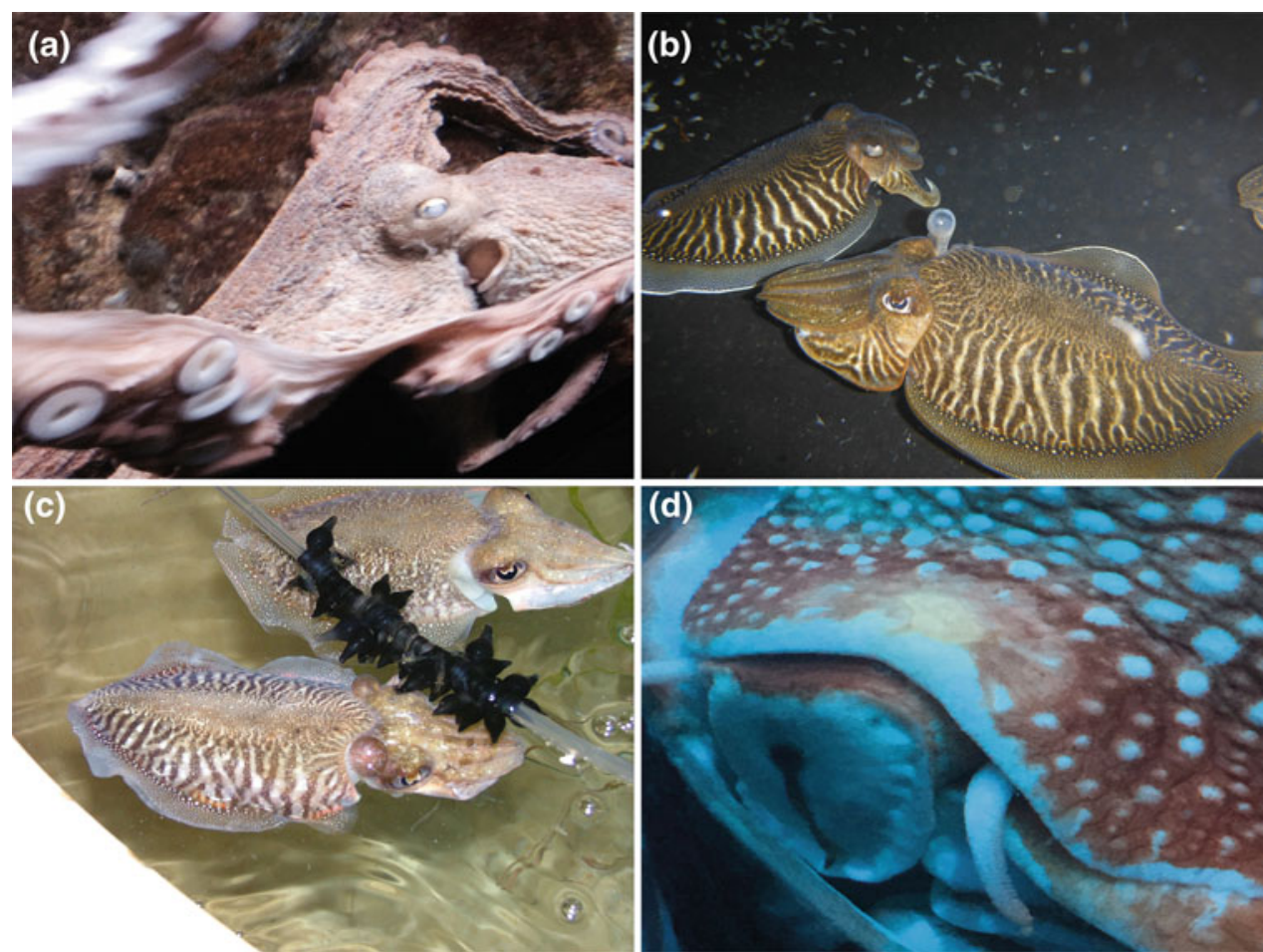

originated by a fungus, which will generate pigment loss has been seen in captive individuals (Fig. 13.2d) and previously reported by Scimeca (2011). The inexistence of idiopathic bulbus protusions in nautilus is most likely due to the anatomy of the eye, which is more primitive than that of other cephalopods. However, excessive mucus production around the eyes can suggest a more serious condition or infection and further diagnostics would be required to determine that it is not a potentially fatal mucodegenerative disease (Barord 2014).

\subsubsection{Shell Wounds/Fracture}

Cuttlefish have an internal shell, commonly known as the cuttlebone or sepion, which corresponds to approximately $9 \%$ of the animal volume, acts as a rigid buoyancy device, and is made of a matrix of calcium carbonate (Denton 1961; Denton and Gilpin-Brown 1961, 1973; Birchall and Thomas 1983; Jacobs 1996), in its aragonite polymorph with a mixture of $\beta$-chitin and other protein complexes (Florek et al. 2009; North et al. 2017). This structure is made of a dorsal shield that covers the lamellar matrix below. The latter is arranged as over a hundred superposed narrow chambers and organic membranes. The chambers have a complex internal arrangement of calcified pillars (made from $0.01 \mathrm{~mm}$ thick septa supported by intracameral walls) that allow resisting external pressures greater than $1 \mathrm{MPa}$ (Hewitt 1975; Birchall and Thomas 1983; Checa et al. 2015;
North et al. 2017). The buoyancy and movement in the water column of cuttlefish is attained through the cuttlebone by: (a) varying the volume of gas space in these chambers and, therefore, of the overall cuttlebone density by moving liquid into or out of those via an osmotic process (Denton et al. 1961; Denton and Gilpin-Brown 1973) and (b) being highly porous $(93 \%)$ and having a low specific gravity (Checa et al. 2015). The gas inside the cuttlebone has traces of $\mathrm{CO}_{2}, 2-$ $3 \%$ of $\mathrm{O}_{2}$ and the remaining is $\mathrm{N}_{2}$ (Denton and Taylor 1964).

Despite having a low occurrence (Sherrill et al. 2000), the fracture of the cuttlebone is one the most common pathologies reported to occur when holding cuttlefishes in captivity. We believe that the higher the occurrence, the lower the welfare the overall rearing conditions, which might be related to available space, tank colour, light conditions or even sex ratios (Sykes and Gestal 2014). It is commonly seen in mature animals due to fighting or banging against the tank walls (Hanlon and Forsythe 1990b; Hanley et al. 1999).

Cuttlebone pathologies in captivity can be categorized into fractures that are (a) partial, in the distal (striated siphuncular zone) and proximal tips (Fig. 13.3a and b, respectively); (b) full transversal (Fig. 13.3c and e); and (c) full longitudinal (Fig. 13.3i and 1). Any of these may or may not include the rupture of the tissues that separate the cuttlebone from the viscera (Fig. 13.3h) and the possible consequent exposure to seawater (Fig. 13.3f, g and k). When the latter happens the individual will die in a few days.

There is an additional pathology related to the cuttlebone. This is characterized by the disruption of the mantle tissue of 

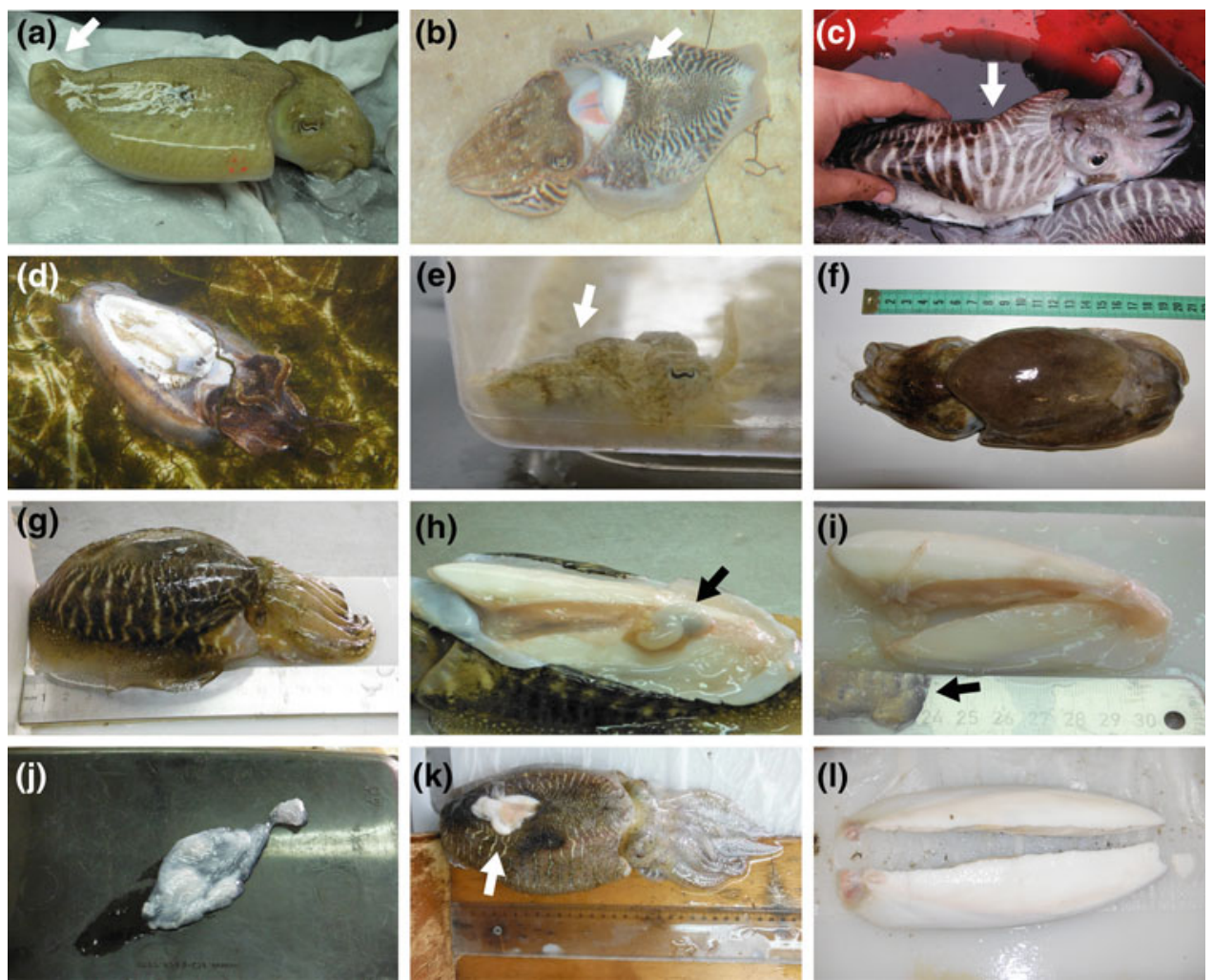

Fig. 13.3 Shell fracture in S. officinalis: a fracture at the distal tip of the cuttlebone; $\mathbf{b}$ fracture at the proximal tip of the cuttlebone; c fracture in the middle of the cuttlebone; d live female where the cuttlebone is not present; $\mathbf{e}$ fracture in the middle of the cuttlebone with increased production of the shell; $\mathbf{f}$ and $\mathbf{g}$ shell fracture in a female and a male (respectively), where the animal is trying to re-unite the shell by massively producing a solution of calcium carbonate; $\mathbf{h}$ detail of shel fracture of animal in $(\mathbf{g})$, where part of the digestive system (stomach and caecum) has passed between the shell parts; $\mathbf{i}$ detail of the broken shell and tissue regeneration; $\mathbf{j}$ detail of tissue regeneration of shell; $\mathbf{k}$ male exhibiting a shell fracture and exposure of digestive system organs (stomach, caecum and digestive gland duct appendages) through the skin; I detail of shell fracture of animal in (k)

$\mathrm{i}$ and j) (Checa et al. 2015) and up to $100 \mathrm{~mL}$ of slightly milky fluid that accumulates between the dermis and the cuttlebone (Hanley et al. 1998).

Feeding conditions (malnutrition) will also affect the proper development of the cuttlebone, generating aberrant forms in juveniles and adults (Boletzky 1974). Black lines in the striated siphuncular zone [Fig. 13.4b; (Keupp 2012)] are usually seen in underfed or starving animals.

Black lines have also been recorded in nautilus and are often found with new shell growth in captivity. However, they are not considered to be detrimental to the health or welfare of the nautilus or linked to nutritional deficit (Barord 2014). Further analysis of nautilus shells under scanning electron microscope (SEM) suggests that the individuals kept in aquaria display a shell made of disorderly crystalline structures when compared to those living in the wild (Moini et al. 2014). It is hypothesised that these differences are due to lower $\mathrm{Ca}$ and $\mathrm{Mg}$ concentrations in the shell; and the resulting brittleness or shell deformities are due to the lack of equilibrium in the biomineralisation process. 
Fig. 13.4 Fungus or parasites in cephalopods eggs: a-c fungi infestation in Octopus insularis eggs (photos courtesy of Érica Vidal); $\mathbf{d}-\mathbf{f}$ sponges attached to $S$. officinalis eggs; $\mathbf{g}-\mathbf{f}$ fungi infestation in $O$. vulgaris eggs
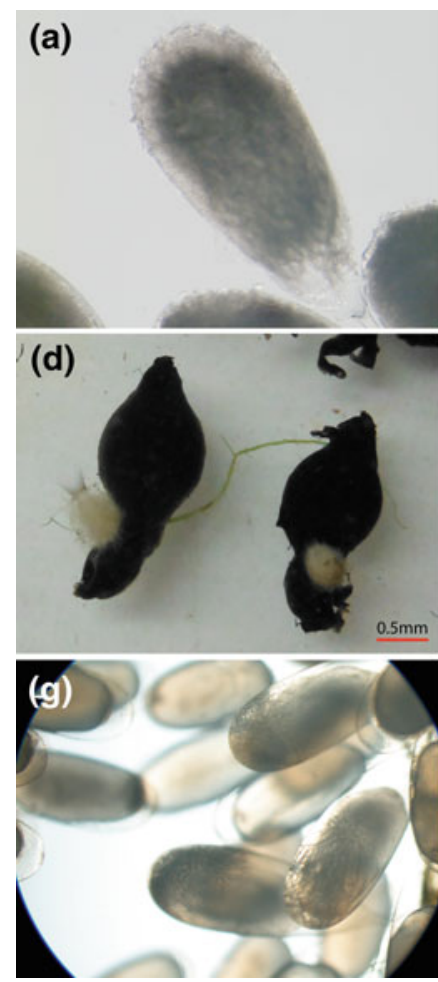

(b)
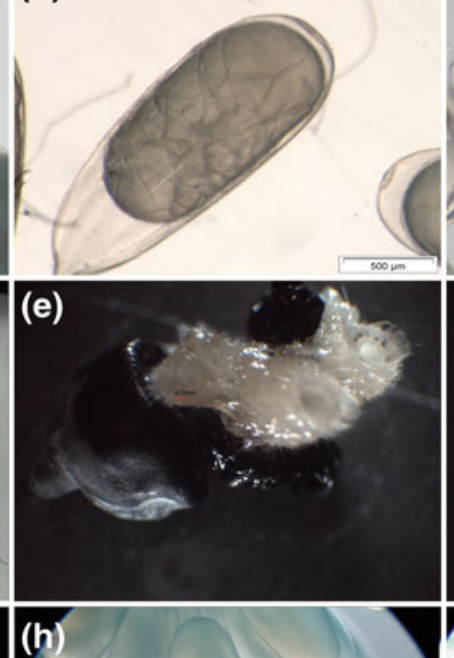

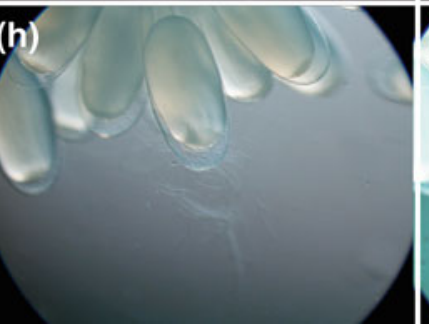

(c)
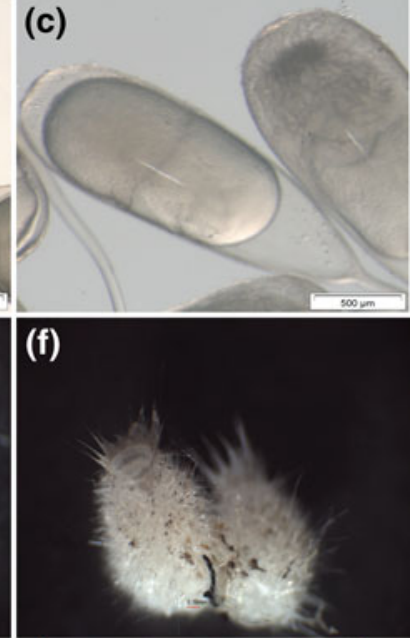

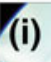

(i)

\subsection{Egg Infections and Cephalopods Malformations}

One of the major issues when keeping eggs of cephalopods through embryogenesis is the eventual spread of fungus (Sykes et al. 2006). However, reports of such occurrence are very scarce. In cuttlefish, fungal activity may be prevented by using the methods described in Sykes et al. (2014a).

Fungal infections in cephalopods were reported to be very limited and are mostly relate to eggs and embryos (Sykes and Gestal 2014; Fiorito et al. 2015). They are reviewed in detail in Chap. 4, but, in here, we report the existence of fungus and possible parasites in cephalopod eggs kept in a captive environment. Both eggs of Octopus insularis (Fig. 13.4a-c) and Octopus vulgaris (Fig. 13.4g-f) displayed mycelia covering the chorion at early stages of embryonic development in Érica Vidal laboratory (Center for Marine Studies, Universidade Federal do Paraná, Brasil) and Eduardo Almansa laboratory (Instituto Español de Oceanografia, Centro Oceanográfico de Canarias, Spain), respectively. In September 2013, at the Sykes laboratory (CCMAR, Universidade do Algarve, Portugal), Sepia officinalis eggs obtained in captivity aborted their development due to an infestation by siliceous sponges that penetrated the chorion (Fig. 13.4d-f). The causes for such infestations are surely due to the seawater quality in the systems, which most probably did not have any sterilization or any appropriate filter prior to the application of the disinfection agent (being the latter either physical or chemical). Fungal activity may be prevented in cuttlefish by individualizing the eggs and using a special tank setup that promotes their gentle movement and proper oxygenation (Sykes et al. 2006, 2014a). This setup has been replicated for rearing other cephalopod eggs through embryogenesis under captivity.

Despite cuttlefish $S$. officinalis non-viable eggs (Fig. 13.5) were classified and described by Sykes et al. (2014a), similar reports are lacking for other cephalopods. As regards $S$. officinalis, the most typical non-viable eggs are those described as orange (Fig. 13.5a), grey and white (Fig. 13.5b), and malformations (Fig. 13.5c). It is known that non-viable eggs also occur in nature but, until now, there is not a trend that might explain the high variability of their occurrence in captivity (Sykes et al. 2013, 2017).

Overall, malformations are even less reported than existing pathologies in cephalopods. Malformations of the cuttlebone have been reported in literature for $S$. officinalis (Ruggiero 1980; Battiato 1983) and other cuttlefish (Keupp 2012). A cuttlebone with a full transversal fracture might regenerate (Fig. 13.3j) with an excess of calcified material in the dorsal shield (Fig. 13.6a). While repairing the cuttlebone, cuttlefish uses a similar process of lamellar deposition to the normal construction being self-organized layer-by-layer as seen with CT-Scan (X-ray computed tomography; Fig. 13.6c and d). The same cuttlebone shows signs of possible decay of the last lamella and black lines in 
Fig. 13.5 Non-viable eggs of $S$. officinalis, according to the nomenclature given in Table 11.2 of Sykes et al. (2014): a Orange eggs; b Grey and White eggs; c Malformation eggs
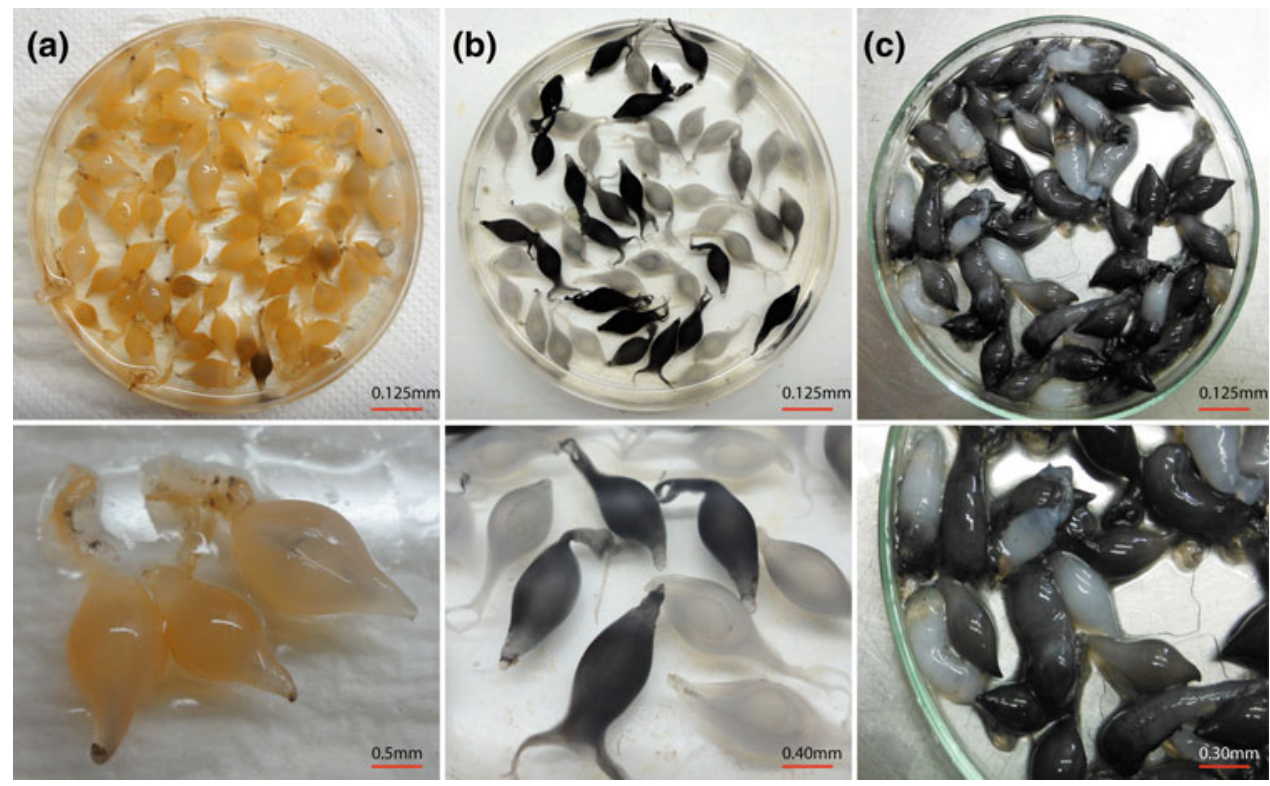

the striated siphuncular zone (Fig. 13.6b). The use of $\mathrm{x}$-ray-computed tomography will allow a better knowledge on the process of cuttlebone repair (Tiseanu et al. 2005) or eventually in nautilus (Hoffmann et al. 2018), even in living organisms.

Other types of malformations exist and are related to the eye (Fig. 13.7a, b), fin (Fig. 13.7a, c), arms (Fig. 13.7e, f) and mantle to arm tissue (Fig. 13.7g) development in cuttlefish and octopus. This was previously reported by Hanlon and Forsythe (1990b). Neoplasia (Fig. 13.7d) is not common in cephalopods (Scimeca 2011) but will result in massive death of animals. Hanlon and Forsythe (1990b) reported that at least two authors have verified the existence of 'tumours' in cuttlefish and wild octopus, but the description of such is related to something completely different to what is seen in Fig. 13.7d. Interestingly, malformations (in this case, the split of an arm into 3 new arms) might develop due to regeneration of an arm after a wound by biting (Fig. 13.7h, i). Arm regeneration is described in literature for cuttlefish (Tressler et al. 2014) and octopus (Shaw et al. 2016). There are no causes reported for these malformations.
Fig. 13.6 Cuttlebone regeneration in S. officinalis: $\mathbf{a}$ and $\mathbf{b}$ anterior and posterior image of cuttlebone that suffered a transversal shell fracture in the middle and regenerated with an increased amount of shell in the upper part; $\mathbf{c}$ and $\mathbf{d}$ CT-Scan of the same cuttlebone from the side and from above respectively, where the growth rings are perfectly visible (images courtesy of René Hoffmann)
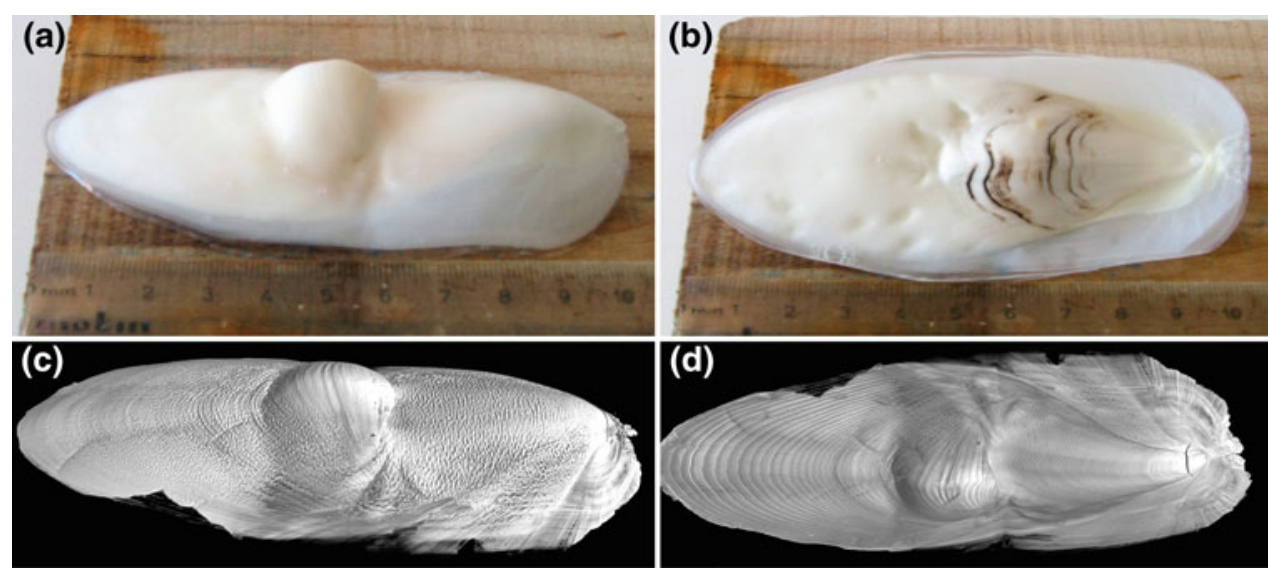
Fig. 13.7 Malformations in development of specific organs in cephalopods: a malformation in development of the $S$. officinalis fin and eye in a newly hatched hatchling; b malformation of the eye in a $S$. officinalis hatchling; c malformation of the fin in a $S$. officinalis juvenile; $\mathbf{d}$ neoplasia in the head of a newly hatched $S$. officinalis; $\mathbf{e}$ and $\mathbf{f}-$

malformations of the arms in $O$. vulgaris paralarvae (only 3 arms and absence of arms, respectively); $\mathbf{g}$ malformation of the connecting muscle of the mantle to the arms in a $O$. vulgaris juvenile; $\mathbf{h}$ and i development of three arms in one arm that was subject to biting in $O$. vulgaris juveniles
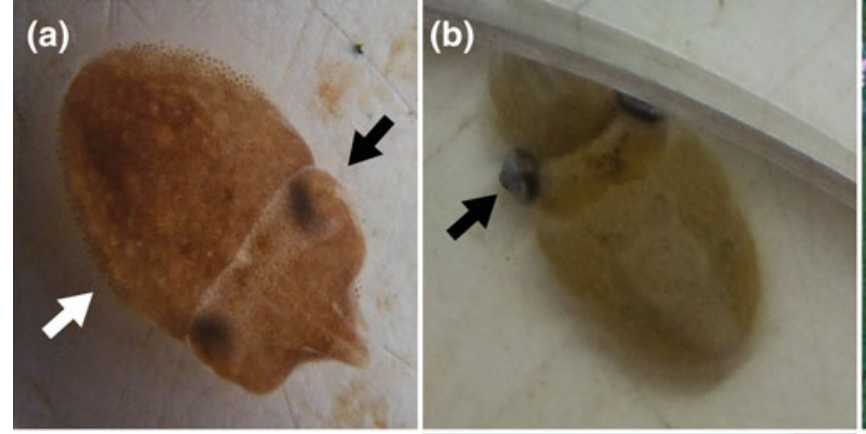

(d)
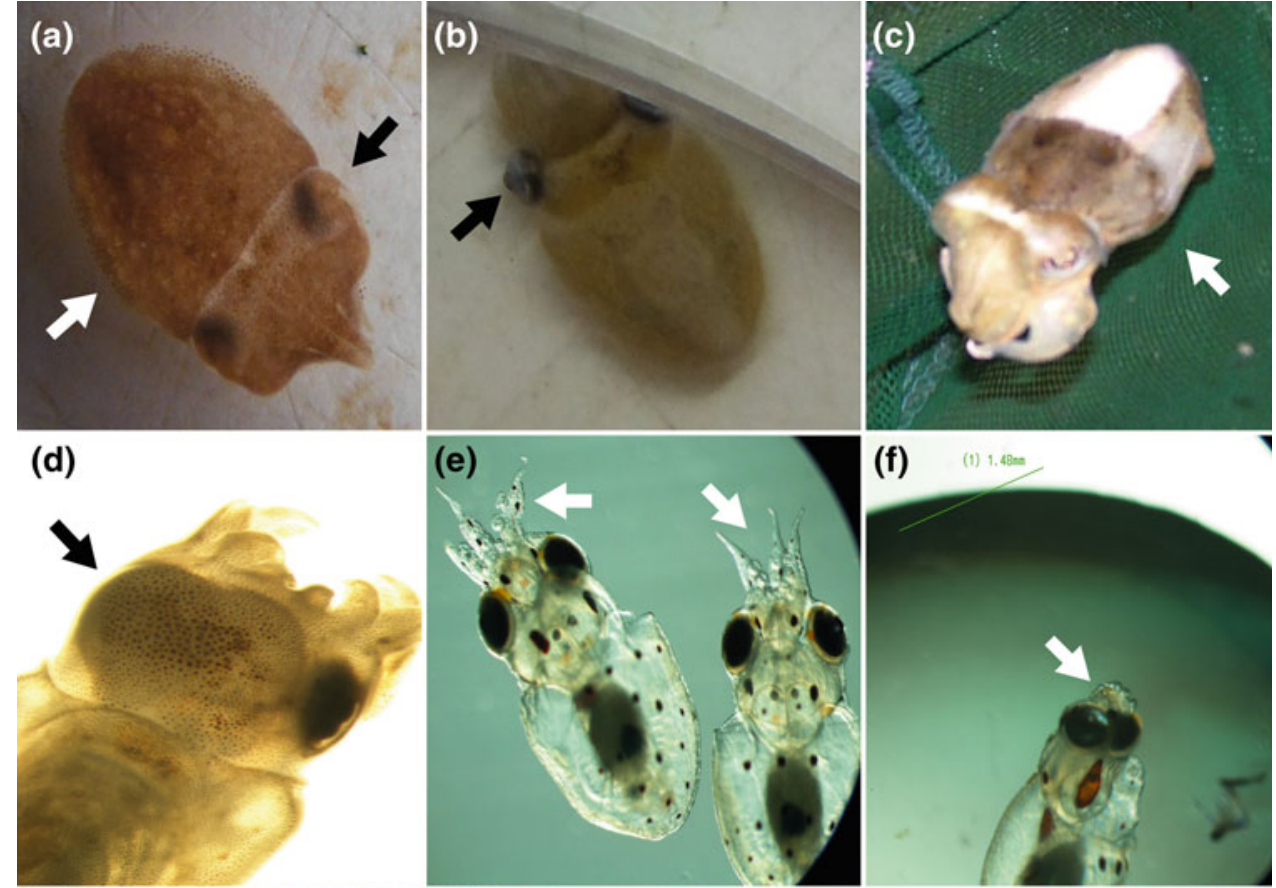

(f)
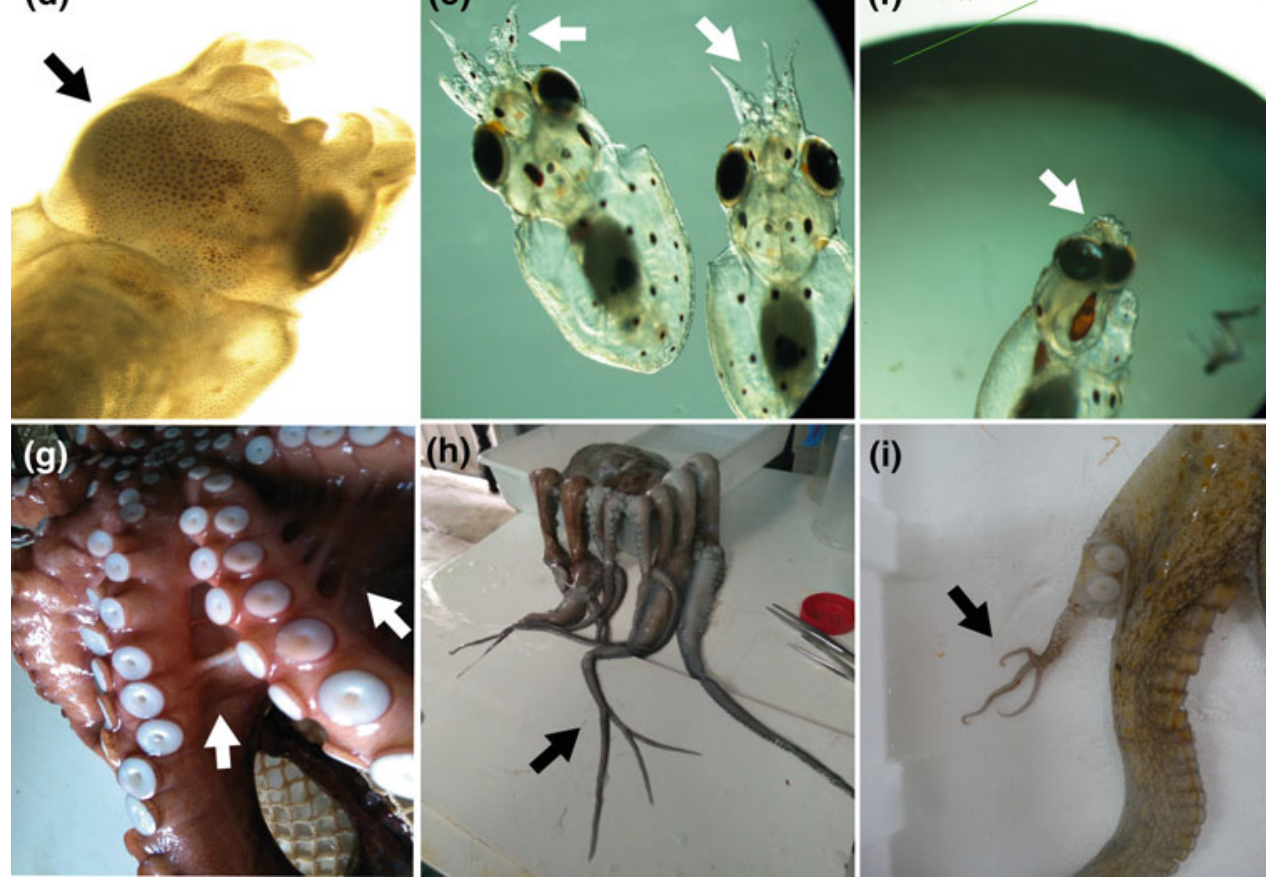

\subsection{Chemical (Water Quality) Damage Related Pathologies}

Cephalopods are marine animals, and as such, they are influenced by the seawater chemical quality, at collection or after being filtered in open, semi-open and closed systems. According to Sykes and Gestal (2014), the impact of diseases/lesions increases with the physicochemical quality and existing stress (which might be generated due to handling or housing conditions), which might promote a suppression of the immune response and proliferation of opportunistic microorganisms. The guidelines for the care and welfare of cephalopods in research (Fiorito et al. 2015) provide a list of water quality criteria for optimum health and welfare of cephalopods in its Appendix 2 and their routine monitoring, while Hanlon (1990) and Smith et al. (2011) described the basic filtering of the seawater systems used for housing cephalopods. Species-specific conditions for every life stage may also be found in Iglesias et al. (2014).
A low seawater $\mathrm{pH}$ has an effect on the carriage of oxygen blood pigments but not in all the species, such as $S$. officinalis juveniles which displays an acid-base regulatory ability (Gutowska et al. 2008, 2010a). However, as a response, this species will increase the calcification of its cuttlebone that may affect its buoyancy function (Gutowska et al. 2010b). On the other hand, hypercapnia promoted reduced growth, extended embryogenesis and smaller cuttlebones (with denser cuttlebone laminae) in embryos and hatchlings (Sigwart et al. 2016).

Colmers et al. (1984) reported the absence or malformation of the statolith and the gravity receptor system and also the absence of cupulae of the angular acceleration receptor systems in seven species of coleoid cephalopods (Octopus joubini, O. maya, O. bimaculoides, S. officinalis, Loligo vulgaris, L. pealei, and L. plei). This condition was described to affect the control and orientation in cephalopods and was concluded that it was due to the lack of strontium in seawater (Hanlon et al. 1989a).

Still concerning rearing in regards to seawater trace elements, despite the copper role in cephalopod haemocyanins 
(Decleir et al. 1978; Thonig et al. 2014), Paulij et al. (1990) verified that copper concentrations of $50-200 \mathrm{ppb} \mathrm{Cu}^{2+}$ exerted shorter embryogenesis and premature hatching in $S$. officinalis, while Establier and Pascual (1983) reported that $0.08 \mathrm{ppm}$ of copper will provoke total mortality in freshly laid eggs in the same species. According to Smith et al. (2011) copper is toxic to all cephalopods. There are some reports (Kuba, personal communication) that an excess of copper in seawater might generate a similar orientation problem and death in S. officinalis. This is probably due to this metal either triggering or inhibiting the phenoloxidaselike activity, which is implicated in the innate immune system (Lacoue-Labarthe et al. 2009). On the other hand, $6 \mathrm{ppm}$ of copper in seawater (used as a way to increase the availability of this trace element) has been used in $O$. vulgaris paralarvae rearing (Garrido et al. 2014) or even up to $115 \mathrm{ppm}$ in formulated feeds for juveniles of this same species (Sancho et al. 2015) without deleterious effects. The differences found between $S$. officinalis and $O$. vulgaris might be due to the possibility of this trace element being essential for the proper development of the latter, as suggested by Villanueva and Bustamante (2006) and García-García and Cerezo-Valverde (2006).

\subsection{Concluding Remarks}

Despite cephalopods being kept in captivity for more than 50 years, our knowledge regarding their pathologies are scarcely reported in literature. This chapter focused on the on mechanical (physical) and chemical (water quality) related pathologies. This is a research field in need of more attention in the years to come, not only because of existing EU welfare legislation, and that arising in other non-EU countries, but also because of the intrinsic importance of this subject in cephalopod maintenance/rearing/culture (Sykes and Gestal 2014). From the several pathologies that are already identified in the laboratory, the community has established the basics for healing and antibiotics application [see Forsythe et al. (1990) and Hanlon and Forsythe (1990a)], and changes to culture setups (some examples given in here). However, the overall existing knowledge regarding the exact causes, its effects and posology for healing is poor when compared with what is available in fish. This is a major gap in our knowledge if we want to provide the best welfare conditions to the animals of this class. Therefore, not only further research is needed but its availability as scientific reports is of major importance.

Acknowledgements The authors would like to thank both Dr. Érica Vidal and Dr. René Hoffmann for allowing us to use their photos and images in this chapter. AVS was funded through Fundação para a Ciência e a Tecnologia (FCT) Investigator Grant (IF/00576/2014). FCT
(Project SEPIABREED PTDC/MAR/120876/2010 and UID/Multi/ 04326/2016), PROMAR (Project SEPIATECH 31.03.05.FEP.002) and Mar2020 (Project SEPIACUL MAR-02.01.01-FEAMP-0053) funded this work. EA acknowledges the funding of OCTOMICs (Project AGL2017-89475-C2-2-R) and OCTOWELF (Project AGL2013-49101-C2-1-R) to this chapter. This work benefited from networking activities carried out under the COST ACTION FA1301, and is considered a contribution to the COST (European COoperation on Science and Technology) Action FA1301 'A network for improvement of cephalopod welfare and husbandry in research, aquaculture and fisheries' (http://www.cephsinaction.org/).

\section{References}

Andouche A, Bassaglia Y (2016) Coleoid cephalopod color patterns: adult skin structures and their emergence during development in Sepia Officinalis. Vie Milieu 66:43-55

Barord GJ (2014) 1-800 Diagnose My Nautilus. Drum and Croaker 24-34

Battiato A (1983) Su un sepiostario aberrante di Sepia officinalis L. (Cefalopoda, Sepiidae). Thalassia Salentina 12/13:152-153

Birchall JD, Thomas NL (1983) On the architecture and function of cuttlefish bone. J Mater Sci 18:2081-2086

Boletzky SV (1974) Effects of continuous malnutrition on development of cuttlebone in Sepia officinalis L. (Mollusca, Cephalopoda). B Soc Zool Fr 99:667-673

Boletzky SV, Overath H (1991) Shell fracture and repair in the cuttlefish Sepia officinalis. In: Boucaud-Camou E (ed) La SeicheThe Cuttlefish, pp 69-78. Centre de Publications de la Université de Caen, France

Boyle PR (1991) The UFAW handbook on the care and management of the cephalopods in the laboratory. UFAW, Herts

Brown C, Garwood MP, Williamson JE (2012) It pays to cheat: tactical deception in a cephalopod social signalling system. Biol Lett 8:729_ 732

Budelmann BU (1998) Autophagy in octopus. S Afri J Mar Sci 20:101-108

Budelmann BU (2010) Cephalopoda. In: The UFAW Handbook on the care and management of laboratory and other research animals. Wiley-Blackwell, pp 785-817

Čadež V, Škapin SD, Leonardi A et al (2017) Formation and morphogenesis of a cuttlebone's aragonite biomineral structures for the common cuttlefish (Sepia officinalis) on the nanoscale: revisited. J Coll Interface Sci 508:95-104

Campinho MA, Oliveira AR, Sykes AV (2017) Olfactory-like neurons are present in the forehead of common cuttlefish, Sepia officinalis Linnaeus, 1758 (Cephalopoda: Sepiidae). Zool J Linnean Soc:zlx083

Checa AG, Cartwright JHE, Sanchez-Almazo I et al. (2015) The cuttlefish Sepia officinalis (Sepiidae, Cephalopoda) constructs cuttlebone from a liquid-crystal precursor. Sci Rep 5

Colmers WF, Hixon RF, Hanlon RT et al (1984) Spinner cephalopods - defects of statocyst suprastructures in an invertebrate analog of the vestibular apparatus. Cell Tissue Res 236:505-515

Decleir W, Vlaeminck A, Geladi P et al (1978) Determination of protein-bound copper and zinc in some organs of the cuttlefish Sepia officinalis L. Comp Biochem Physiol 60B:347-35

Denton EJ (1961) The buoyancy of fish and cephalopods. Progr Biophys Mol Biol 11:177-234

Denton EJ, Gilpin-Brown JB (1961) Buoyancy of cuttlefish, Sepia officinalis (L). J Mar Biol Assoc UK 41:319-342

Denton EJ, Gilpin-Brown JB, Howarth JV (1961) The osmotic mechanism of the cuttlebone. J Mar Biol Assoc UK 41:351-364 
Denton EJ, Taylor DW (1964) Composition of gas in chambers of cuttlebone of Sepia officinalis. J Mar Biol Assoc UK 44:203-207

Denton EJ, Gilpin-Brown JB (1973) Floatation mechanisms in modern and fossil cephalopods. Adv Mar Biol 11:197-268

Di Cristina G, Andrews P, Ponte G et al (2015) The impact of Directive 2010/63/EU on cephalopod research. Invert Neurosci 15:1-7

Dröscher A (2016) Pioneering studies on cephalopod's eye and vision at the Stazione Zoologica Anton Dohrn (1883-1977). Front Physiol 7

Establier R, Pascual E (1983) Effects of cadmium and copper on the development of eggs of Sepia officinalis L. Invest Pesq 47:143-150

EU (2010) Directive 2010/63/EU of The European Parliament and of the Council of 22 September 2010 On the protection of animals used for scientific purposes. In: Union E (ed) Official Journal European Union, pp 33-79

Feral JP (1978) Regeneration of arms of cuttlefish Sepia officinalis L (Cephalopoda, Sepioidea): 1-Morphological study. Cah Biol Mar 19:355-361

Feral JP (1979) Regeneration of the arms of Sepia officinalis L (Cephalopoda, Sepioidea): 2-Histologic and Cytologic Study. Cah Biol Mar 20:29-42

Feral JP (1988) Wound-healing after arm amputation in Sepia officinalis (Cephalopoda, Sepioidea). J Invertebr Pathol 52:380-388

Fiorito G, Affuso A, Anderson DB et al (2014) Cephalopods in neuroscience: regulations, research and the 3 Rs. Invertebr Neurosci 14:13-36

Fiorito G, Affuso A, Basil J et al (2015) Guidelines for the care and welfare of cephalopods in research - a consensus based on an initiative by CephRes, FELASA and the Boyd Group. Lab Anim 49:1-90

Florek M, Fornal E, Gomez-Romero P et al (2009) Complementary microstructural and chemical analyses of Sepia officinalis endoskeleton. Mat Sci Eng C-Bio S 29:1220-1226

Ford LA, Alexander SK, Cooper KM et al (1986) Bacterial populations of normal and ulcerated mantle tissue of the squid, Lolliguncula brevis. J Inv Pathol 48:13-26

Forsythe JW, Hanlon RT, Lee PG (1987) A synopsis of cephalopod pathology in captivity. In: Williams TD (ed) 18th annual conference of the international association for aquatic animal medicine. Monterey Bay Aquarium, Monterey, California, pp 130-135

Forsythe JW, Hanlon RT, Lee PG (1990) A formulary for treating cephalopod mollusc diseases. In: Perkins FO, Cheng TC (eds) Third International Colloquium on Pathology in Marine Aquaculture Academic Press Inc., Gloucester Point, Virginia (USA), 2-6 Oct 1988, pp 51-63

García-García B, Cerezo-Valverde J (2006) Optimal proportions of crabs and fish in diet for common octopus (Octopus vulgaris) ongrowing. Aquaculture 253:502-511

Garrido D, Rodríguez EM, Felipe B et al (2014) Influence of copper on Octopus vulgaris paralarvae rearing. In: Aquaculture Europe 2014 — adding value, p 2. Donostia-San Sebastián, Spain

Gutowska MA, Portner HO, Melzner F (2008) Growth and calcification in the cephalopod Sepia officinalis under elevated seawater $p \mathrm{CO}_{2}$. Mar Ecol Progress Ser 373:303-309

Gutowska MA, Melzner F, Langenbuch M et al (2010a) Acid-base regulatory ability of the cephalopod (Sepia officinalis) in response to environmental hypercapnia. J Comp Physiol B 180:323-335

Gutowska MA, Melzner F, Portner HO et al (2010b) Cuttlebone calcification increases during exposure to elevated seawater $p \mathrm{CO}_{2}$ in the cephalopod Sepia officinalis. Mar Biol 157:1653-1663

Hanley JS, Shashar N, Smolowitz R et al (1998) Modified laboratory culture techniques for the European cuttlefish Sepia officinalis. Biol Bull 195:223-225

Hanley JS, Shashar N, Smolowitz R et al (1999) Soft-sided tanks improve long-term health of cultured cuttlefish. Biol Bull 197:237-238
Hanlon RT, Forsythe JW, Cooper KM et al (1984) Fatal penetrating skin ulcers in laboratory-reared octopuses. J Inv Pathol 44:67-83

Hanlon RT, Forsythe JW, Lee PG (1988) External pathologies of cephalopods in captivity. In: Cheng TC, Perkins FO (eds) Third international colloquium on pathology in marine aquaculture. Academic Press Inc., Gloucester Point, Virginia (USA), pp 17-18

Hanlon RT, Bidwell JP, Tait R (1989a) Strontium is required for statolith development and thus normal swimming behavior of hatchling cephalopods. J Exp Biol 141:187-195

Hanlon RT, Yang WT, Turk PE et al (1989b) Laboratory culture and estimated life span of the Eastern Atlantic squid, Loligo forbesi Steenstrup, 1856 (Mollusca: Cephalopoda). Aqua Fish Manage 20:15-34

Hanlon RT (1990) Maintenance, rearing and culture of teuthoid and sepioid squids. In: Adelman WJ Jr, Arnold JM, Guilbert DL (eds) Squid as Experimental Animals. Plenum Press, New York, pp 35-61

Hanlon RT, Forsythe JW (1990a) Diseases caused by microorganisms. In: Kinne O (ed) Diseases of Mollusca: Cephalopoda, pp 23-46. Biologische Anstalt Helgoland, Hamburg

Hanlon RT, Forsythe JW (1990b) Structural abnormalities and neoplasia. In: Kinne O (ed) Diseases of marine animals, pp 203204. Biologische Anstalt Helgoland, Hamburg

Hanlon RT, Messenger JB (1996) Cephalopod behaviour. Cambridge University Press, New York

Hewitt RA (1975) Analysis of aragonite from cuttlebone of Sepia officinalis L. Mar Geol 18:M1-M5

Hoffmann R, Lemanis RE, Falkenberg J et al (2018) Integrating 2D and $3 \mathrm{D}$ shell morphology to disentangle the palaeobiology of ammonoids: a virtual approach. Paleontology 61:89-104

How MJ, Norman MD, Finn J et al (2017) Dynamic skin patterns in cephalopods. Front Physiol 8:393

Iglesias J, Fuentes L, Villanueva R (2014) Cephalopod culture. Springer, Netherlands

Jacobs DK (1996) Chambered cephalopod shells, buoyancy, structure and decoupling: history and red herrings. Palaios 11:610-614

Keupp H (2012) Atlas zur paläopathologie der cephalopoden. Berliner Paläobiologische Abhandlungen 12:1-392

Kingston ACN, Kuzirian AM, Hanlon RT et al (2015) Visual phototransduction components in cephalopod chromatophores suggest dermal photoreception. J Exp Biol 218:1596-1602

Lacoue-Labarthe T, Bustamante P, Horlin E et al (2009) Phenoloxidase activation in the embryo of the common cuttlefish Sepia officinalis and responses to the $\mathrm{Ag}$ and $\mathrm{Cu}$ exposure. Fish Shellfish Immun 27:516-521

Moini M, O'halloran A, Peters AM et al (2014) Understanding irregular shell formation of Nautilus in aquaria: chemical composition and structural analysis. Zool Biol 33:285-294

North L, Labonte D, Oyen ML et al (2017) Interrelated chemicalmicrostructural-nanomechanical variations in the structural units of the cuttlebone of Sepia officinalis. APL Mater 5:116103

Oestmann DJ, Scimeca JM, Forsythe J et al (1997) Special considerations for keeping cephalopods in laboratory facilities. Cont Topics Lab Animal Sci 36:89-93

Paulij WP, Zurburg W, Denuce JM et al (1990) The effect of copper on the embryonic-development and hatching of Sepia officinalis $L$. Arch Environ Con Tox 19:797-801

Ponte G, Dröscher A, Fiorito G (2013) Fostering cephalopod biology research: past and current trends and topics. Invert Neurosci :1-9

Reimschuessel R, Stoskopf MK (1990) Octopus automutilation syndrome. J Inv Pathol 55:394-400

Rohrbach B, Schmidtberg H (2006) Sepia arms and tentacles: model systems for studying the regeneration of brachial appendages. Vie Milieu 56:175-190 
Ruggiero L (1980) Un esemplare aberrante di Sepia officinalis L. (Cephalopoda, Sepiidae). Thalassia Salentina 10:131-132

Sancho MDC, Valverde JC, Sironi JS et al (2015) Is copper supplementation required in formulated feeds for octopus vulgaris (Cuvier, 1797)? J Shellfish Res 34:473-480

Scimeca JM, Oestmann DJ (1995) Selected diseases of captive and laboratory reared cephalopods. Proc Int Assoc Aquatic Anim Med 27:26-79

Scimeca JM (2011) Cephalopods. In: Lewbart GA (ed) Invertebrate medicine, pp 113-125. Wiley-Blackwell

Shaw TJ, Osborne M, Ponte G et al (2016) Mechanisms of wound closure following acute arm injury in Octopus vulgaris. Zool Lett 2:1-10

Sherrill J, Spelman LH, Reidel CL et al (2000) Common cuttlefish (Sepia officinalis) mortality at the National Zoological Park: implications for clinical management. J Zoo Wildlife Med 31:523-531

Sigwart JD, Lyons G, Fink A et al (2016) Elevated $p C O(2)$ drives lower growth and yet increased calcification in the early life history of the cuttlefish Sepia officinalis (Mollusca: Cephalopoda). ICES J Mar Sci 73:970-980

Smith JA, Andrews PLR, Hawkins P et al (2013) Cephalopod research and EU Directive 2010/63/EU: requirements, impacts and ethical review. J Exp Mar Bio Ecol 447:31-45

Smith SA, Scimeca JM, Mainous ME (2011) Culture and maintenance of selected invertebrates in the laboratory and classroom. ILAR J 52:153-164

Sykes AV, Domingues PM, Correia M et al (2006) Cuttlefish culturestate of the art and future trends. Vie Milieu 56:129-137

Sykes AV, Baptista FD, Gonçalves RA et al (2012) Directive 2010/63/EU on animal welfare: a review on the existing scientific knowledge and implications in cephalopod aquaculture research. Rev Aqua 4:142-162

Sykes AV, Pereira D, Rodríguez C et al (2013) Effects of increased tank bottom areas on cuttlefish (Sepia officinalis, L.) reproduction performance. Aqua Res 44:1017-1028

Sykes AV, Domingues P, Andrade JP (2014a) Sepia officinalis. In: Iglesias J, Fuentes L, Villanueva R (eds) Cephalopod culture, pp 175-204. Springer, Netherlands

Sykes AV, Gestal C (2014) Welfare and diseases under culture conditions. In: Iglesias J, Fuentes L, Villanueva R (eds) Cephalopod culture, pp 97-112. Springer Netherlands

Sykes AV, Koueta N, Rosas C (2014b) Historical review of cephalopods culture. In: Fuentes L, Villanueva R, Iglesias J (eds) Cephalopod culture. Springer, Netherlands, pp 59-75

Sykes AV, Alves A, Capaz JC et al (2017) Refining tools for studying cuttlefish (Sepia officinalis) reproduction in captivity: in vivo sexual determination, tagging and DNA collection. Aquacult 479:13-16

Thonig A, Oellermann M, Lieb B et al (2014) A new haemocyanin in cuttlefish (Sepia officinalis) eggs: sequence analysis and relevance during ontogeny. Evodevo 5

Tiseanu I, Craciunescu T, Mandache NB et al (2005) $\mu$-X-ray computer axial tomography application in life sciences. J Optoelectron Adv M 7:1073-1078

Tressler J, Maddox F, Goodwin E et al (2014) Arm regeneration in two species of cuttlefish Sepia officinalis and Sepia pharaonis. Invert Neurosci 14:37-49

Villanueva R, Bustamante P (2006) Composition in essential and non-essential elements of early stages of cephalopods and dietary effects on the elemental profiles of Octopus vulgaris paralarvae. Aquacult 261:225-240
Open Access This chapter is licensed under the terms of the Creative Commons Attribution 4.0 International License (http://creative commons.org/licenses/by/4.0/), which permits use, sharing, adaptation, distribution and reproduction in any medium or format, as long as you give appropriate credit to the original author(s) and the source, provide a link to the Creative Commons licence and indicate if changes were made.
The images or other third party material in this chapter are included in the chapter's Creative Commons licence, unless indicated otherwise in a credit line to the material. If material is not included in the chapter's Creative Commons licence and your intended use is not permitted by statutory regulation or exceeds the permitted use, you will need to obtain permission directly from the copyright holder. 